\title{
Agreement and unlocking at the edge
}

\author{
Kenyon Branan \& Colin Davis*
}

\begin{abstract}
A growing body of work argues that Agree has the effect of "unlocking" certain domains, phases, such that otherwise illicit extraction from them becomes permitted (Rackowski \& Richards 2005, van Urk and Richards 2015, Halpert 2016, 2018, Branan 2018). First, we address when such unlocking is required. While some works argue that unlocking is only needed for extraction from deep within a phase, others argue that all extraction requires it. We argue in support of the former view, based on Chichewa facts reported in Mchombo (2004, 2006). Second, we consider the relationship between unlocking effects and phase theory more generally. We argue that the possibility of unlocking indicates that material deep within a phase must not be rendered inaccessible by spellout, or else unlocking effects should be impossible. We explore how unlocking might be handled in the cyclic linearization theory of phases (Fox \& Pesetsky 2005, a.o.) which leaves syntactic elements accessible post-spellout.
\end{abstract}

Keywords. phases; extraction; agreement; spellout

1. Introduction. Recent work in syntactic theory argues for a connection between agreeing with certain domains, taken to be phases (Chomsky 2000, 2001, a.o.), and extraction out of them. In particular, works in this vein propose that agreeing with a phase can cause otherwise impossible extraction from it to succeed (Rackowski \& Richards 2005, Halpert 2016, 2018, Branan 2018). A central claim of this research is that the phase itself normally intervenes for probing of elements deeper than its edge, preventing extraction from non-edge positions within the phase under normal circumstances. However, a prior Agree relation with the containing phase prevents it from interrupting a subsequent Agree dependency. Thus a second probe can Agree with an element deep within the phase, with movement of that element occurring as a reflex:

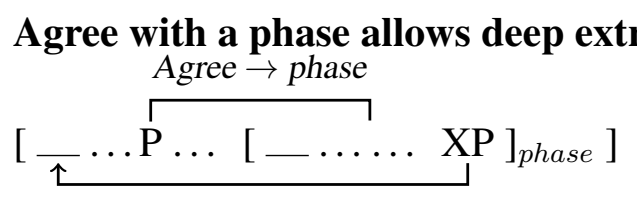

In this paper, we addresses two issues related to the theory of unlocking effects.

The first issue we consider is the choice of unlocking theory. The authors mentioned above argue that there are two ways that extraction which crosses a phase boundary may take place: either by successive-cyclic movement through the edge of the phase, or by unlocking the phase via Agree in the way just discussed. In contrast, van Urk \& Richards 2015 argue on the basis of Dinka (Nilotic) that both of these operations are needed - a phase must be targeted by Agree, and the extracting element must move via the phase edge. We provide a more in-depth look at these theories in $\S 2$, and argue in $\S 3$ that the first sort of theory is correct, based on evidence from Chichewa (Bantu) reported in Mchombo (2004, 2006). As we'll see, in Chichewa the leftmost

\footnotetext{
${ }^{*}$ We thank Norvin Richards, David Pesetsky, and audiences at ACAL 49, WCCFL 36 and the 93rd annual meeting of the LSA. Authors listed alphabetically. Kenyon Branan, National University of Singapore (kgbranan@nus.edu.sg) \& Colin Davis, Massachusetts Institute of Technology (colind@ mit.edu).
} 
element in the nominal domain may generally be dislocated; but other elements may be dislocated only when the nominal as a whole controls verbal agreement morphology. This can be explained neatly under the "either-or" theory of unlocking, which allows for multiple methods of phase escape, but is unexpected under the "both-and" theory, which affords no special status to edges.

Our second concern, addressed in $\S 4$, is the compatibility of unlocking with phase theory more generally. All versions of phase theory adopt the view that phases delimit a domain from which extraction (among other operations) is restricted, but differ in how that restriction is derived. One prominent approach suggests a Phase Impenetrability Condition, arising as a result of features on elements within a phase being removed by the operation spellout. This operation applies to the phase's complement, making its contents inaccessible for later operations (Chomsky 2000, 2001, 2008, a.o.). However, movement to the phase edge escapes spellout of the complement, permitting subsequent agreement or movement. Under this hypothesis, elements remaining in the complement of the phase should be unrecoverable by later probes. But this is what the version of unlocking theory that we argue for entails. Here we have a point of tension, which we suggest can be resolved by moving towards a phase theory without a strict Phase Impenetrability Condition. In parti-cular, we consider the cyclic linearization approach to phase locality (Fox \& Pesetsky 2005, and many others) which derives successive-cyclic movement from the nature of spellout and linearization, without positing that spellout makes elements inaccessible to further syntactic operations.

2. Phases and unlocking. Much of this paper deals with the juxtaposition of phase theory and unlocking effects. In this section we first overview the parts of phase theory relevant to the discussion. We then introduce the basics of unlocking, focusing on extraction from the nominal domain.

2.1 PHASES AND EDGES. As just previewed, an influential idea in contemporary syntactic theory is that the derivation proceeds in phases (Chomsky 2000, 2001, 2008, a.o), which delimit the domain of syntactic operations. The set of phases commonly assumed includes vP, CP, and in many cases DP; we will assume throughout that DP is indeed a phase. Phases restrict the derivation in a particular way; some but not all elements within a phase may be targeted by operations triggered by elements not contained in the phase, as per the Phase Impenetrability Condition.

A widely-held hypothesis is that this property of phases is reducible to the behavior of spellout, triggered when a phase is merged with higher structure. Spellout applies to the complement of a phase head, stripping elements within the complement of all formal features, and sending them to the interfaces (PF, LF). However, spellout does not apply to the phase head itself, nor its specifier(s). The phase head thus bifurcates the structure in two, as schematized in (2).

\section{(2) Phases constrain access to further operations}

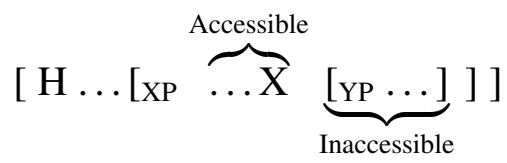

While the complement of the phase is inaccessible post-spellout, movement from complement to specifier of the phase escapes spellout, permitting further movement, as in (3). 
(3) The phase edge (specifier) provides an escape hatch for movement

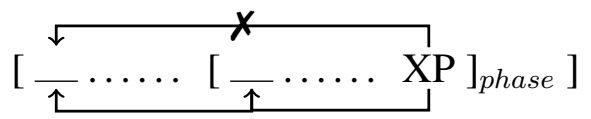

This view of phases and how to escape them allows us to explain why syntactic operations seem to have a cyclic, local, punctuated character. Phases restrict the domain of syntactic operations; intermediate operations become necessary to construct apparently long-distance dependencies. Under the approached just sketched, the inaccessibility of material in the phase's complement post-spellout is the driving force behind this state of affairs. Later in the paper, we will describe how this approach to phases is in tension with unlocking theory. First, we must introduce unlocking theory, and provide the evidence for the version of it we defend here.

2.2 UNLOCKING BY AGREEMENT. As previewed in the introduction, one version of unlocking theory proposes that there are two methods of phase escape (Rackowski \& Richards 2005, Halpert 2016, 2018, Branan 2018). One method is movement through the phase edge, as just discussed, and another is letting Agree unlock the phase first, which allows later extraction that skips the phase edge, as schematized in (4) once more:

\section{(4) Agree with a phase allows bypassing of the phase edge Agree $\rightarrow$ phase

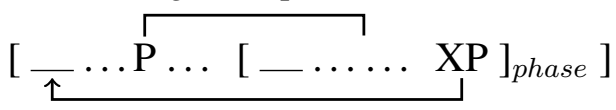

Branan (2018) presents evidence for this view from cross-linguistic restrictions on extraction from DP. The upshot is that extraction from DP requires the DP to have been Agreed with-DP edges being generally inaccessible for movement_-given the assumption that DPs are phases.

An illustrative example comes from Northern Ostyak (Nikolaeva 1999 [Uralic, Russia]). As we see in (5), Northern Ostyak allows sub-extraction of possessors from subjects, which obligatorily control verbal agreement.

Imi ijolti [ lik-dl__ ] et-dl nawdrnin pela
woman always anger-3SG come-T.3sS frog to
'This woman, her anger always comes to the frog.'

Importantly, Northern Ostyak has an optional process of object agreement. When object agreement takes place, extraction from the object is possible:
Juwan motta [ xot-əl
John before house- $\underline{3 S G}$ see-T-SG.1SG.3OBJ

'I saw John's house before.'

However, when object agreement does not occur, as in (7), extraction from the object is impossible:
(7) *Juwan motta [ xot-əl John before house-3SG see-T-1SG 'I saw John's house before.'


These facts can be understood in fairly straightforward fashion. In a language like Northern Ostyak, the edge of DP is not a good target for movement. As a result, extraction from DP requires that DP to be unlocked by Agree, since that is the only method of phase escape available. In (6) the object is not Agreed with and is not unlocked, and as a result it is an opaque domain for further probing and extraction. In (7), in contrast, the object is Agreed with and is unlocked, and therefore is transparent for further probing and extraction.

3. When unlocking must apply: evidence from Chichewa. We have mentioned that while some theories allow extraction to be facilitated either by unlocking, or by movement via the phase edge, there is also work arguing that both of these must occur for successful cross-phasal movement (van Urk \& Richards 2015). In this section, we discuss a set of facts from Chichewa which we argue are suggestive of the former theory.

3.1 WhEN AGREEMENT AND EXTRACTION GO TOGETHER. To begin, we will examine some circumstances of extraction and agreement in Chichewa, in which the latter is contingent on the former. Our source of Chichewa facts is Mchombo (2004, 2006), who discusses how the Object Marker (OM) constrains discontinuous DP formation in this language. Generally, according to Mchombo, the presence of the OM is optional-perhaps conditioned by discourse factors. In certain circumstances involving the formation of discontinuous DPs, however, the OM is obligatory.

As we see in (8), adjective extraction from DP is allowed in Chichewa. The dislocated adjective, yókálamba, appears at the left edge of the clause, and is construed with the postverbal direct object mikángo. Note that both the adjective and object are of noun class 4 , and that there is a class $4 \mathrm{OM}$ in the verbal complex.

Yókálamba anyání $\quad \begin{aligned} & \text { a-na-1́-gúl-ílá } \\ & \text { 4SM-aged }\end{aligned}$ 2-baboons 2SM-PST-4OM-buy-APPL-FV 6-hoes 6-these 6SM-blunt mikángo __ ]

4.lions

'The baboons bought the aged lions these blunt hoes.' Mchombo (2004, ex. 21b)

Contrast (8) with (9), which is ungrammatical. Example (9) contains a dislocated adjective $z a$ $k u d a$, and a direct object mbûzi, with which it could potentially be construed. Note the lack of a concomitant class $10 \mathrm{OM}$ in the verbal complex, in contrast with (8). This suggests that this sort of dislocation is contingent on the presence of the OM.

(9) *Zakuda atsíkáná á mfúmu a-a-gul-á

10SM-black 2-girls 2AssocM 9-chief 2SM-PERF-buy-FV 10.goats

'The chief's girls have bought black goats.'

Mchombo (2006, ex. 4a)

Other elements may be extracted from nominals in Chichewa, with a similar requirement that an OM which cross-references the nominal extracted from must appear on the verb. In (10) we see that the class 2 demonstrative awa may be dislocated and construed with the object DP headed by alenje, provided that there is a class $2 \mathrm{OM}$ on the verb. This suggests that extraction from DP in Chichewa is generally contingent on the presence of the OM. 
Note, before we move on, the relative order of noun, demonstrative, and adjective in the Chichewa DP. Demonstratives and adjectives are ordered to the right of the nominal head, and these require the presence of the OM to be extracted, as we've seen.

$$
\begin{aligned}
& \text { alenje awa ópúsa } \\
& \text { hunter these foolish } \\
& \text { 'these foolish hunters' }
\end{aligned}
$$$$
\text { Adapted from Mchombo (2006, ex. 2a) }
$$

Notice that $\mathrm{N}$ itself occupies the left edge of the DP. As we will see next, extraction of $\mathrm{N}(\mathrm{P})$ is different than extraction of the elements considered so far.

3.2 WHEN AGREEMENT AND EXTRACTION COME APART. We will now examine extraction of nominal heads in Chichewa. As we see in (12), this process is indeed possible. Here the class 2 nominal alenje appears at the left edge of the clause; it may be construed with the post-verbal class 2 demonstrative $a w a$ and adjective ópúsa, and is furthermore interpreted with a thematic role normally associated with VP internal nominals. Note the presence of the class $2 \mathrm{OM}$ on the verb.

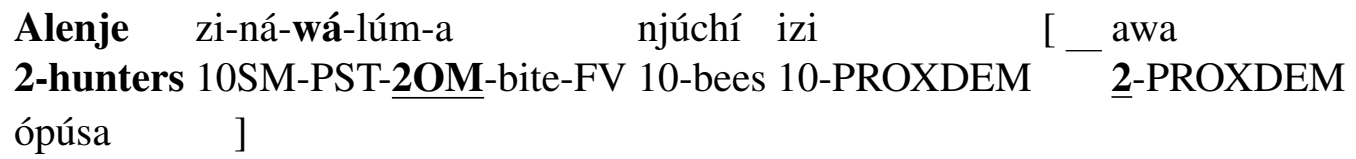

'These bees bit these foolish hunters.'

Mchombo (2004, pg. 50, ex. 16c)

Interestingly, as we see in (13), nominals behave differently than adjectives and demonstratives with respect to sub-extraction. In (13) we see that the class 10 nominal mbîzi may appear at the left edge of the sentence and be construed with the class 10 post-verbal adjective, and receive a thematic role normally associated with low, PV internal nominals. However-interestingly-here there is no class $10 \mathrm{OM}$ on the verb. Nevertheless the sentence is acceptable.

$$
\begin{aligned}
& \text { Mbûzi atsíkáná á mfúmu a-a-gul-á } \quad\left[\begin{array}{l}
\text { zákúda } \\
\text { 10-goats 2-girls 2-AssocM 9chief }
\end{array}\right. \text { 2S-PERF-buy-FV } \\
& \text { 'Goats, the chief's girls have bought black (ones).' } \\
& \text { 10SM-black }
\end{aligned}
$$

In other words, what we see in Chichewa is that nominals that control agreement morphology are more transparent for extraction, whereas nominals that do not are less transparent. However, nominals that fail to control agreement morphology are not totally opaque. Extraction from these nominals appears to be possible provided the element undergoing extraction originates at the left edge of the Chichewa DP, which in this case, is $\mathrm{N}(\mathrm{P})$. This element can be extracted whether the OM is present or not, as (12) and (13) showed. See Mchombo (2006) for more facts of this sort.

3.3 The OM involves AgREE. The facts so far are suggestive not only of an analysis involving unlocking, but of a particular theory of unlocking which privileges edges - if movement via the 
phase edge is available, unlocking need not occur. Before such an analysis can be provided, we will need to establish that the OM in Chichewa is involves an Agree dependency with the nominal whose features it tracks.

Our main argument for this comes from the fact that the OM in Chichewa displays locality requirements that are characteristic of Agree: the OM can only cross-reference the highest internal argument, showing that it is subject to independently identified locality/economy constraints on syntactic dependencies, such as the Minimal Link Condition (MLC, Chomsky (1995), a.o.) and related concepts like superiority and the A-over-A condition.

An independent restriction on word order and the OM must first be discussed before we can proceed: nominals which control the OM must appear at the right edge of the Chichewa VP. With this in mind consider (14), involving the OM in a derived ditransitive context. According to Mchombo, the benefactive applicative argument anyáni, which here controls the OM, normally appears to the left of the direct object. Common tests for c-command furthermore indicate that this benefactive applied argument is higher in the clause than the direct object zitúmbûwa.

\section{Alenje a-ku-wá-phík-il-á _zítúmbûwa ${ }_{D O}$ anyáni $_{I O}$ 2-hunters 2SM-PRES-2OM-cook-APPL-FV 8-pancakes 2-baboons}

'The hunters are cooking the baboons some pancakes.' Mchombo (2004, pg. 83, ex. 41a)

Now contrast (14) with (15). Here we see that the direct object-which we have established to be lower in the clause than the benefactive-is unable to control the OM.
*Alenje a-ku-zí-phík-il-á
anyáni $_{I O}$ _ zítúmbûwa ${ }_{D O}$
2.hunters 2SM-PRES-80M-cook-APPL-FV 2-baboon 8-pancakes

'The hunters are cooking the baboons some pancakes.' Mchombo (2004, pg. 83, ex. 41b)

Recall that in a typical transitive clause, the direct object can control the OM. This fact indicates that the presence of the benefactive argument disrupts the typically available dependency between the direct object and the OM. This is an expected result, given the hypothesis that the OM involves an Agree relation. It is commonly assumed that Agree relationships prefer to be established with the relevant element closest to the head which initiates probing, as a result of the general locality constraints on syntactic dependencies mentioned above. The benefactive argument ccommands and thus is closer to the OM probe than the direct object, and thus economy/locality demands that the OM probe target the benefactive argument, rather than the direct object.

As expected, this is not an effect peculiar to benefactive applicatives. Consider (16), involving a case of possessor raising in which the raised possessor controls the OM. Normally the raised possessor precedes the possessum, but in this case the possessor cross-referenced by the OM is rightmost in $\mathrm{VP}$ - analogous to what we saw in ditransitives above.

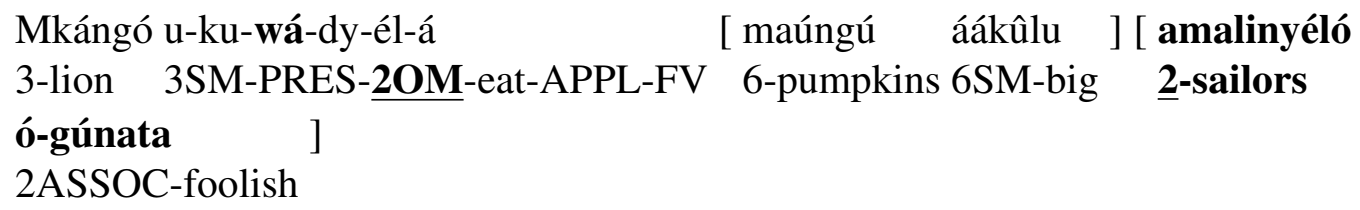

'The lion is eating for the foolish sailors (their) big pumpkins.'

Mchombo (2004, pg. 55, ex. 22e) 
Again according to Mchombo, common tests for asymmetric c-command suggest that the raised possessor asymmetrically c-commands the possessum. Mchombo states that in the possessor raising construction, the possessum is unable to control the OM. From this we learn that the locality restriction on the OM probe is general: the OM can only target the highest element in the VP, which we expect given the MLC, if the OM does involve an Agree relationship as we suggests an aside, for completeness sake, (17) shows us that sub-extraction of non-edge elements from raised possessors is acceptable in Chichewa, provided that the OM cross-references the possessor. Mchombo shows that in these possessor raising contexts, comparable extraction from the possessum is not possible, as expected, given that this element cannot be targeted by the OM.

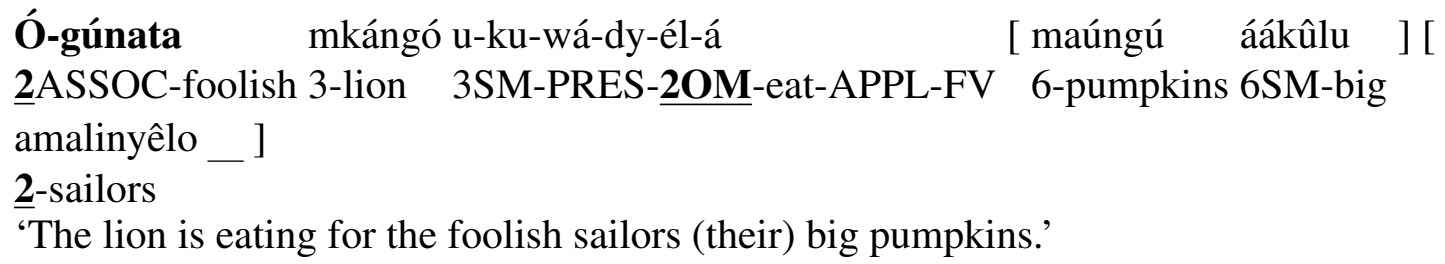

We turn now to another locality constraint on the OM and its concomitant effect on extraction from the nominal it cross-references. Consider first (18), which serves as a baseline case. We see in (18) an instance of recursive possession.

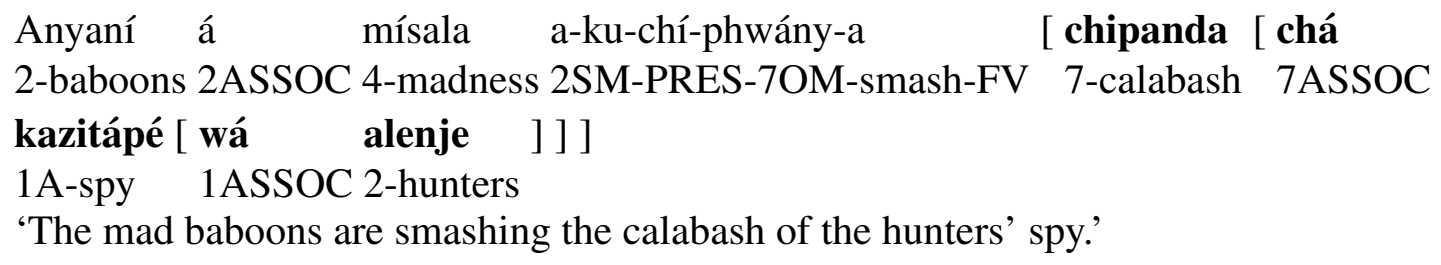

Mchombo (2004, pg. 60, ex. 29)

The direct object chipanda ('calabash') is-as we expect-able to control the OM. As we see in (19), it is possible to extract the possessor of the direct object controlling OM.

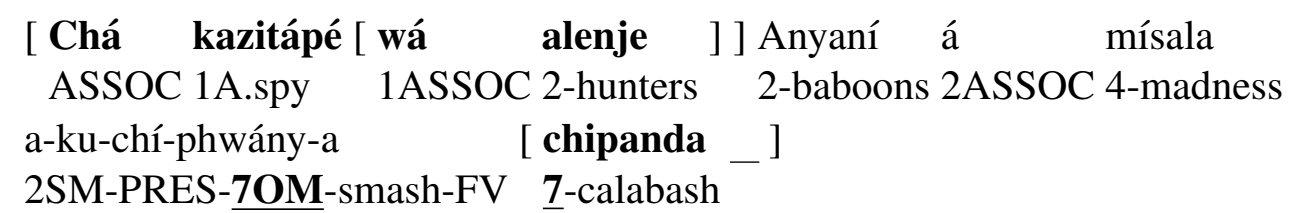

The mad baboons are smashing the calabash of the hunters spy.

Mchombo (2004, pg. 60, ex. 30a)

In contrast, as we see in (20), it is not possible to extract the possessor of the possessor of the element that controls OM. ${ }^{1}$ This shows us that the transparency for extraction that the OM typically grants is restricted only to the DP cross-referenced by the OM, but not subsequent DPs embedded within it. Therefore the direct object is transparent for extraction, since it has been targeted by the $\mathrm{OM}$, but its possessor has not been targeted by the OM and thus remains opaque.

\footnotetext{
${ }^{1}$ We might wonder whether the ungrammaticality of results from the features of the OM clashing with the features of the fronted constituent. Mchombo shows that making these features match does not improve the example, as expected if the real problem here is a locality violation.
} 
*[ Wá alenje ] Anyaní á mísala a-ku-chí-phwány-a [ 1assoc 2-hunters 2-baboons 2assoc 4-madness 2SM-PRES-7OM-SMASH-FV chipanda [ chá kazitápé _ ] ]

7-calabash 7ASSOC 1A.spy

The mad baboons are smashing the calabash of the hunters spy.

Mchombo (2004, pg. 60, ex. 30b)

This is as expected, if the OM involves an Agree relation-the structurally highest DP in a recursive possession structure will be targeted by the OM first, after which it ceases probing. Consequently, further embedded DPs cannot be unlocked.

To sum up, the restrictions examined in this subsection follow straightforwardly if the OM is the reflex of an Agree relation: Agree targets the closest DP bearing relevant features, explaining the restrictions in various circumstances where multiple DP are in competition to control the OM.

3.4 IMPLEMENTATION. We have seen that extraction from DP in Chichewa is subject to a particular requirement: When extracting from a DP, that DP must control the OM on the verb, unless the extracted element is the nominal head of the DP, which normally appears at the left edge of DP. We argue that this result is consistent with the "either/or" version of unlocking theory, which only requires unlocking when moving from the non-edge of a phase.

We assume that the N-initial order of the Chichewa DP is derived by movement of NP to the edge of DP (21). Such movement is proposed for independent reasons in Cinque (2005), and for the Kordofanian language Moro in Jenks (2010).

\section{(21) NP movement to spec-DP $\left[{ }_{D P} \mathbf{N P}_{k}\right.$ D Dem Adj _ $k$ ]}

Since NP occupies the edge of the Chichewa DP, agreement is not required for its extraction: it is at the edge of the DP phase, and is therefore accessible for probing and concomitant movement. But extraction from the non-edge does require agreement, as we've seen. We argue that this is because Agree with the DP unlocks it for further probing, allowing an A-probe to subsequently search past the edge of DP, as schematized in (22). 


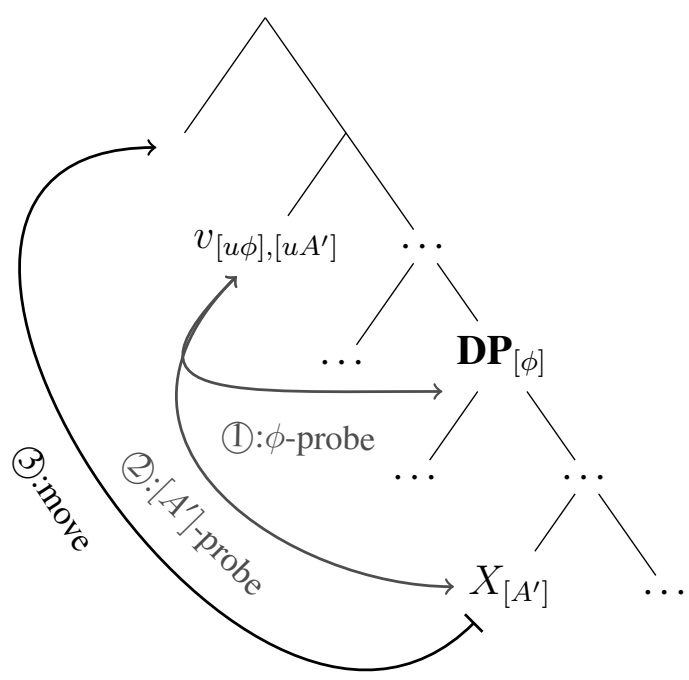

If an extracting adjective or demonstrative could pass through spec-DP, the edge of this phase, Agreement with DP should not be necessary here. However, this position is occupied by NP in Chichewa, precluding movement to this 'escape hatch' position. ${ }^{2}$ In contrast, by virtue of being at the DP edge, Agreement with DP is not a prerequisite for extraction of NP.

3.5 UNLOCKING IN DiNKA. van Urk \& Richards (2015) proposed that extraction from phase edges in fact does require unlocking, contrary to what we argued above, based on the interaction of extraction and EPP effects in Dinka (Nilotic). van Urk \& Richards show that Dinka has two positions in the clause, which they identify as spec-CP and spec-vP, that in the basic case must be filled by a DP. However, they argue that extraction from an embedded clause passes through and satisfies the EPP for these positions. This explains the fact that the spec-CP and spec-vP of a clause that extraction has exited can remain empty on the surface, as (23) illustrates with the two gaps marked in the embedded clause:

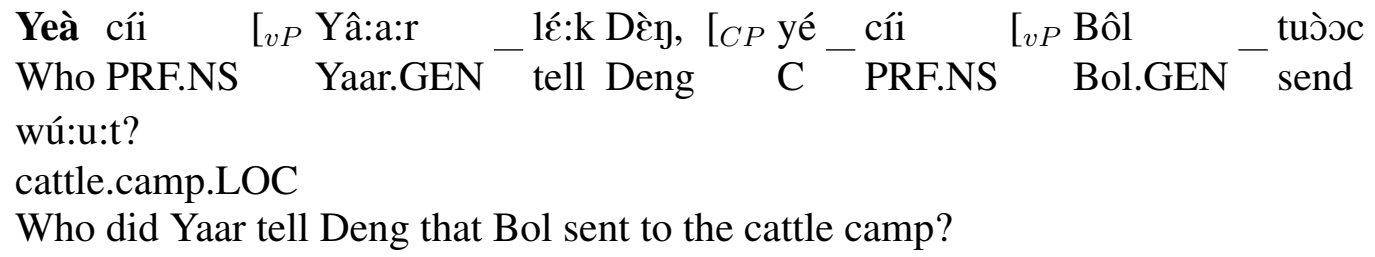

van Urk and Richards argue that the embedded CP itself in such contexts satisfies the EPP for the matrix v, however. Consequently, they argue that there is an Agree relation between matrix $v$ and the embedded $\mathrm{CP}$, triggering movement of $\mathrm{CP}$ to spec-vP (followed by extraposition of $\mathrm{CP}$ ).

If this analysis is right, the embedded CP was Agreed with by v, even though the extracting phrase passed through spec-CP. Having reached the edge of CP, Agree should not have been neces-

\footnotetext{
${ }^{2}$ Implicit here is the claim that Chichewa permits only one spec-DP. Alternatively, we could claim that Chichewa D lacks an $\mathrm{A}^{\prime}$-probe, or that anti-locality constraints block the relevant elements from moving through the DP edge. This ban on exiting a phase that already has a specifier is reminiscent of WH-island effects, whereby a filled spec-CP degrades extraction from CP (as in ${ }^{*} \mathrm{How}_{j}$ did you wonder [which problem] ${ }_{k}$ they should solve ${ }_{-k}-j$ ?).
} 
sary to unlock that CP. So why was it Agreed with? van Urk and Richards suggest that Agree was needed because both movement via the phase edge and unlocking are necessary for extraction, in contrast to what we have proposed based on Chichewa.

There turns out to be evidence that the relevant high position in the Dinka CP is not in fact at the very edge of the embedded clause. The peripheral position which van Urk \& Richards argue that extracting phrases pass through is preceded by an overt complementizer-for instance, notice that the leftmost gap in the embedded clause in (23) above is preceded by a complementizer yé. We independently see this position right of the complementizer filled in non-extraction contexts, as (24) below shows:
A-cá
táak, ke Cà:n bí wít
tíaam
3SG-PRF.1SG think C Can FUT wrestling win.TR
I think that Can will win the wrestling

If the filled post-C position in (24) is really the same as the position passed through by extraction in (23) above, as van Urk and Richards argue, then the account defended in the present paper predicts that embedded CPs in Dinka will indeed need to be unlocked to permit extraction. To see why, notice once more that the gap in CP in (24) is preceded by a complementizer. If a phrase extracting from $\mathrm{CP}$ exits via this position below the complementizer, then extraction from the embedded $\mathrm{CP}$ is not in fact taking off from the $\mathrm{CP}$ edge. This is precisely the circumstance in which the present paper predicts that unlocking should be required to facilitate extraction. And indeed, van Urk and Richards argue that unlocking does occur here. If there were no complementizer above the extraction site in the embedded clause, we predict that unlocking would not have been necessary.

4. Fitting phase theory and unlocking together. Generally, the possibility of agreement unlocking phases for otherwise impossible extraction raises a puzzle for commonly held theories of locality in movement. Recall in $\S 2$ our discussion of phase theory, where we mentioned the approach to phase impenetrability that involves spellout removing syntactic features from all elements in the complement of a phase head, to make syntactic objects digestible by the PF/LF interfaces. Spellout thus motivates successive-cyclic movement via phase edges, because material that fails to reach the edge is rendered inaccessible by spellout of the complement.

This phase theory sits uneasily with unlocking theory, which posits that extraction from deep within phases is indeed possible under certain circumstances. To maintain both theories, it would be necessary to posit additional mechanisms. On the one hand, we could hypothesize that Agree with a phase somehow 'revives' previously spelled out material, with syntactic features being 'added back' to elements within the phase's complement. This would force us to discard Inclusiveness (Chomsky (995). Another option would be to allow a delay between the completion of a phasal constituent and the spellout of that phase, in the case that the phase will later be targeted by Agree-though this would be admitting a suspicious sort of look-ahead into the system.

Instead of pursuing such approaches, we suggest adopting a different view of what spellout does. The existence of unlocking effects suggests that material lower than the phase's edge is not irretrievably lost. Therefore, if we are to maintain spell-out as a property of phases, we need a way to motivate successive-cyclicity (and certain exceptions to it) without relying on a theory in which spellout effectively removes elements from the syntactic derivation. We will consider how 
unlocking might be reconciled with one such theory, termed cyclic linearization (Fox \& Pesetsky 2005a/b, Sabbagh 2007, Podobryaev 2009, Ko 2007, 2011, 2014, Davis 2019a/b.)

4.1 CYCLIC LINEARIZATION AND SUCCESSIVE-CYCLICITY. Under the cyclic linearization theory, spellout affects entire phases, not just their complement, and has the effect of fixing the relative linear order of elements within the phase. The requirement that extracting phrases successivecyclically pass through the edge of phases results from a more general ban on contradictory linearization statements.

To see how this works, let's consider what would go wrong in a derivation where a wh-phrase moves from an embedded CP in a single leap, rather than pausing at the edge of the $\mathrm{CP}$ being crossed, as in (25). Here the lack of a gap marked in the edge of CP1 signals that in this hypothetical derivation, no successive-cyclic movement occurred.

*Wh-movement that bypasses the CP edge

$\left[C P 2\right.$ What $_{k}$ did you say $\left[C P 1\right.$ that they ate $\left.\left.{ }_{-k}\right]\right]$ ?

When the embedded CP1 spells-out, the wh-phrase will not have started moving. Thus spellout generates the following ordering information for $\mathrm{CP} 1$, where what follows everything in this phase:

\section{Linearization of CP1 (non-successive-cyclic version)}

that $<$ they $<$ ate $<\underline{\text { what }}$

(where $\alpha<\beta$ means $\alpha$ linearly precedes $\beta$ )

Later, what finally moves from the complement of $\mathrm{V}$ in the embedded clause, to the edge of CP2. After such movement occurs, spellout of CP2 generates an ordering in which what precedes all content in $\mathrm{CP} 2$, all of which precedes the content of $\mathrm{CP} 1$ :

\section{Linearization of CP2 (non-successive-cyclic version) \\ $\underline{\text { What }}<$ did $<$ you $<$ say $<$ [content of CP1]}

These two sets of ordering information are in contradiction: (26) tells us that what follows everything in $\mathrm{CP} 1$, but (27) tells us that what precedes everything in $\mathrm{CP} 2$, all of which precedes $\mathrm{CP} 1$. This is a contradiction, since what must both precede and follow the content of CP1. Fox $\&$ Pe-setsky propose that loops of this sort cause derivations to crash at PF. But consider what would happen if what moved to the edge of CP1 before that phase spelled out. In this case, spellout of CP1 would generate the following linearization information:

\section{Linearization of CP1 (successive-cyclic version)}

$\underline{\text { what }}<$ that $<$ they $<$ ate

Here what was determined to precede the content of CP1, just as it will after later movement to the specifier of $\mathrm{CP} 2$. From its landing site in $\mathrm{CP} 2$, what appropriately precedes the content of both phases in the derivation, and no contradiction arises. Importantly, a contradiction was avoided by having what successive-cyclically move to the edge of CP1 before exiting it.

This rationale for successive-cyclic movement does not depend on anything like a Phase Impenetrability Condition. Rather it arises as a consequence of keeping linearization information free of contradictions. Since this theory does involve spellout making elements inaccessible to later syntactic operations, it opens the door to accommodating unlocking effects. In what follows, we'll explore a way to implement unlocking within this framework, by taking a careful look at how 
Fox \& Pesetsky characterize ordering information.

4.2 A LOOPHOLE IN THE SATISFACTION OF ORDERING STATEMENTS. In the above sketch of cyclic linearization, we have used the symbol " $<$ " relatively informally to indicate linear prece-dence. The cyclic linearization approach actually requires a somewhat more complicated definition of the relationship encoded by " $<$ " in order to capture the intuition that traces are not relevant to linearization. This is necessary because if traces were visible to linearization, essentially any instance of non-string-vacuous movement would generate an ordering contradiction. ${ }^{3}$

The relation " $<$ "

Fox \& Pesetsky 2005, ex. 11

An ordering statement of the form $\alpha<\beta$ is understood by PF as meaning that the last element dominated by $\alpha$ and not dominated by a trace precedes the first element dominated by $\beta$ and not dominated by a trace. [where 'trace' is to be understood as 'the lower copy in a movement chain']

The upshot of this definition is that the lower element in a movement dependency, as well as everything dominated by it, is (more or less) ignored by PF-the result of this is that lower copies, and the elements they dominate, cannot be sources of ordering contradictions. An interesting-and for our purposes, useful - corollary of this definition is that if all copies of an element are dominated by a trace, it will never count as a blocker for extraction, or at least, for linearizationsensitive extraction. ${ }^{4}$ The relationship " $<$ " will hold/be satisfied vacuously when all instances of $\alpha$ or $\beta$ are dominated by a trace. We propose that 'unlocking' reflects the creation of just such a chain: that is to say, unlocking involves the phrase targeted by Agree counting as the lower copy in a movement chain.

Mchombo (2006, 2008) argues that the Chichewa OM is what he terms an "incorporated prononimal argument", which we can consider a doubled pronominal clitic. We argued above that the dependency involved in the formation of the OM involves an Agree relation. Preminger (2019) argues on the basis of the Person Case Constraint that clitic doubling indeed involves Agree, followed by movement. Harizanov (2014) as well argues that clitic doubling involves movement of a phrase, followed by morphological merger. We tentatively suggest that unlocking effects arise when the agreement morphology that appears to facilitate unlocking involves, in some sense, a movement dependency of this sort between the domain being unlocked, and the morphology co-varying with its features. That domain is unlocked for extraction due to being treated like a "trace", whose terminals can thus no longer be implicated in ordering contradictions.

The idea here is perhaps abstract, so here is a concrete example of how this approach might derive the unlocking effect. Consider the Chichewa (30), involving extraction of a non-edge element (adjective) from an object with concomitant object marking on the verb:

\footnotetext{
${ }^{3}$ Fox \& Pesetsky ultimately recast their theory in terms of multidominance, but we will make use of the version defined in terms of traces here.

${ }^{4}$ Nothing in this theory is committed to reducing all constraints on extraction to a linearization issue. Under the theory being used here, linearization only constrains the independent movement possibilities made available by syntax.
} 
Yókálamba anyání a-na-í-gúl-1́lá makású awa óbúntha [ 4SM-aged 2-baboons 2SM-PST-40M-buy-APPL-FV 6-hoes 6-these 6SM-blunt mikángo

4-lions

'The baboons bought the aged lions these blunt hoes'

Mchombo (2004, ex. 21b)

When the object DP here spells-out, the derivation will establish that NP precedes the adjective (31a). Assume that this ordering information feeds the production of a corresponding linear string, which will be incrementally built-up by subsequent applications of phase-by-phase spellout (31b).

\section{Spellout of object DP}

(a). Linear precedence: NP $<$ Adj

$\rightarrow$

(b). String: mikángo yókálamba

Later, the DP undergoes Agree and clitic doubling-resulting in the presence of the OM on the verb. This renders that DP a "trace", due to being the lower element in the movement chain created by the formation of that clitic. Because that DP behaves like a trace, the ordering information in (31a) is no longer a possible source of ordering contradictions-PF will ignore that information from now on. As a result, extraction of the adjective to a position that precedes NP will not generate a contradiction. When the vP containing this DP spells out, linearization will learn that $\mathrm{V}$, for instance, precedes DP. The derivation also knows that the NP remaining in DP, and hence following $\mathrm{V}$, will be pronounced mikángo, following the string in (31b) generated when this DP originally spelled-out. So this derivation ultimately allows the remnant of extraction from DP to be pronounced in VP just as we expect, of course with the exception of the extracted element.

A final note is in order about how the sorts of chains we are discussing are pronounced. In many languages, non-initial links in a movement chain are unpronounced. This is why Fox \& Pesetsky require traces to be generally ignored by PF, as encoded in (29) above. The movement op-eration that results in phenomena like clitic doubling must not have this effect, since in Chichewa, for instance, a DP that the OM agrees with is still pronounced, as mentioned. Harizanov (2014) argues that the morphological merger implicated in the formation of doubled clitics results in a re-duced version of the doubled argument. Nunes (2004) argues that the Chain Reduction operation, which deletes all but one link of a movement chain, does not apply when the link of a chain has been reanalyzed by morphology as part of a word. Such a perspective might lead us to expect that a doubled clitic, affixed to some functional head, need not trigger the sort of Chain Reduction that would delete the original argument that is being doubled.

5. Conclusion. This paper had two goals. The first was to examine the mechanics of unlocking effects, by which Agree with a phase facilitates extraction from it. We argued that this property of Agree is only a prerequisite for extraction when movement from the phase's edge is independently unavailable. That is, only extraction directly from deeper within the phase requires unlocking.

The second goal of this paper was to consider the relationship between unlocking effects and phase theory more broadly. We argued that if the interior of phases is completely inaccessible to further syntactic operations after spellout, as predicted by a strict Phase Impenetrability Condi- 
tion, agreement with the phase should not be able to facilitate deep extraction, unless undesirable stipulations are made. We explored an implementation of unlocking in the context of the cyclic linearization theory, which derives the typical necessity for extraction via phase edges without the notion of a Phase Impenetrability Condition.

As far as we know, cyclic linearization is the only phase theory on the market that does not rely on some sort of impenetrability condition. ${ }^{5}$ It is for this reason that we made us of it here. However, any theory that derives the punctuated character of movement operations without phase impenetrability would be equally as compatible with unlocking effects, in principle. We leave it for future work to determine how exactly such concepts should be united.

\section{References}

Branan, Kenyon. 2018. Attraction at a distance: A'-movement and case. Linguistic Inquiry 49. 409-440. https://doi.org/10.1162/ling_a_00278.

Chomsky, Noam. 1995. The Minimalist program. Cambridge, MA: MIT Press.

Chomsky, Noam. 2000. Minimalist inquiries. In Roger Martin, David Michales, Juan Urigareka \& Samuel Jay Keyser (eds.), Step by step: Essays on Minimalist syntax in honor of Howard Lasnik. 89-155. Cambridge, MA: MIT Press.

Chomsky, Noam. 2001. Derivation by phase. In Michael Kenstowicz (ed.), Ken Hale: A life in language. Cambridge, MA: MIT Press.

Chomsky, Noam. 2008. On Phases. In Robert Freidin, Carlos P. Otero \& Maria Luisa Zubizarreta (eds.), Foundational issues in linguistic theory: Essays in honor of Jean-Roger Vergnaud. Cambridge, MA: MIT Press.

Cinque, Guglielmo. 2006. Deriving Greenberg's Universal 20 and its exceptions. Linguistic Inquiry 36. 315-332. https://doi.org/10.1162/0024389054396917.

Davis, Colin P. 2019a. Crossing and stranding at edges. MS, MIT.

Davis, Colin P. 2019b. Possessor extraction in English. MS, MIT.

Fox, Danny \& David Pesetsky. 2005a. Cyclic Linearization and its interaction with other aspects of the grammar. Theoretical Linguistics 31. https://doi.org/10.1515/thli.2005.31.1-2.235.

Fox, Danny \& David Pesetsky. 2005b. Cyclic Linearization of Syntactic Structure. Theoretical Linguistics 31. 1-45. https://doi.org/10.1515/thli.2005.31.1-2.1.

Halpert, Claire. 2016. Argument licensing and agreement. Oxford: Oxford University Press. https://doi.org/10.1093/acprof:oso/9780190256470.001.0001.

Halpert, Claire. 2019. Raising, unphased. Natural Language \& Linguistic Theory 37. 123-165. https://doi.org/10.1007/s11049-018-9407-2.

Harizanov, Boris. 2014. Clitic doubling at the syntax-morphophonology interface. Natural Language \& Linguistic Theory 32(4). 1033-1088. https://doi.org/10.1007/s11049-014-9249-5.

\footnotetext{
${ }^{5}$ Chomsky's (2001) weaker, revised version of the Phase Impenetrability Condition delays phase spellout until the next phase head is merged. This theory leaves more time for extraction to take place - there remains the possibility of a non-phase head extracting something from the phase's complement, until the next phase head arrives. If this were the explanation for phenomena that have the character of unlocking, it would mean that there is some connection between agreeing with a phase, and extraction from that phase being triggered by some non-phase head that is merged before the next phase head. It is not obvious to us that there is any way to justify such a connection, and therefore we have not pursued such an approach to unlocking.
} 
Jenks, Peter. 2010. Deriving adposition and noun phrase structure in Moro. Handout from ACAL 41.

Ko, Heejeong. 2007. Asymmetries in scrambling and cyclic linearization. Linguistic Inquiry 38. 49-83. https://doi.org/10.1162/ling.2007.38.1.49.

Ko, Heejeong. 2011. Predication and edge effects. Natural Language \& Linguistic Theory 29. 725. https://doi.org/10.1007/s11049-011-9143-3.

Ko, Heejeong. 2014. Edges in syntax: Scrambling and cyclic linearization. Oxford: Oxford University Press.

Mchombo, Sam. 2004. The syntax of Chichewa. Cambridge: Cambridge University Press.

Mchombo, Sam. 2006. Linear order constraints on split NPs in Chichewa. ZAS Papers in Linguistics 43.

Nikolaeva, Irina. 1999. Ostyak. Munich: LINCOM Europa.

Nunes, Jairo. 2004. Linearization of chains and sideward movement. Cambridge, MA: MIT Press.

Podobryaev, Sasha. 2009. Postposition stranding and related phenomena in Russian. In G. Zybatow, U. Junghanns, D. Lenertová \& P. Biskup (eds.), Studies in formal Slavic phonology, morphology, syntax, semantics and information structure, Frankfurt: Peter Lang.

Preminger, Omer. 2019. What the PCC tells us about abstract agreement, head movement, and locality. Glossa: A Journal of General Linguistics 4(1). https:/doi.org/10.5334/gjgl.315.

Rackowski, Andrea \& Norvin Richards. 2005. Phase edge and extraction: A Tagalog case study. Linguistic Inquiry 36. 565-599. https://doi.org/10.1162/002438905774464368.

Sabbagh, Joseph. 2007. Ordering and linearizing rightward movement. Natural Language \& Linguistic Theory 25. https://doi.org/10.1007/s11049-006-9011-8.

van Urk, Coppe \& Norvin Richards. 2015. Two components of long-distance extraction: Successive cyclicity in Dinka. Linguistic Inquiry 46. 113-155. https://doi.org/10.1162/LING_a_00177. 